\title{
La lucha antiterrorista en el Perú: agujeros negros legales, agujeros grises y el arduo camino constitucional. Lecciones peruanas para la guerra contra el terrorismo global The anti-terrorist fighting in Peru: legal black holes, gray holes and the arduous constitutional way. Peruvian lessons for the war on global terrorism
}

\section{ABRAHAM SILES VALLEJOS*}

Resumen: El presente trabajo examina, desde el paradigma del Estado constitucional de derecho, la estrategia antiterrorista que desarrolló el Perú. Una de las expresiones de esta lucha antisubversiva fue la instauración casi permanente de los regímenes de excepción y la aprobación de las leyes penales de emergencia, las cuales son analizadas críticamente, pues propiciaron graves afectaciones a los derechos fundamentales. En ese sentido, se muestra, con grave preocupación, la creación por parte del Estado peruano de «agujeros negros» $\mathrm{y}$ «agujeros grises» legales en desmedro de las víctimas de desaparición forzada. Finaliza el autor haciendo un balance de la postura de los órganos jurisdiccionales y el reto que tienen en la construcción del modelo democrático y constitucional de lucha contra el terrorismo.

Palabras clave: Lucha antiterrorista - régimen de excepción - legislación antiterrorista - fuerzas armadas

\begin{abstract}
This paper examines the anti-terrorist strategy developed by Peru from the paradigm of the constitutional rule of law. One expression of this counter-insurgency fight was the nearly permanent establishment of states of emergency and the adoption of criminal emergency laws, which are critically analyzed, because they led to serious results on fundamental rights. In that sense, it is shown, with severe concern, the establishment by the Peruvian Government of legal "black holes" and "gray holes" at the expense of victims of enforced disappearance. The author concludes by assessing the position of the courts and the challenge they have in elaborating a democratic and constitutional model for combating terrorism.
\end{abstract}

Key words: Anti-terror fight - state of emergency - anti-terrorist legislation - military forces

\footnotetext{
* Profesor de Derecho Constitucional de la Pontificia Universidad Católica del Perú (PUCP). Correo electrónico: asiles@pucp.pe. Ponencia presentada en el IX Congreso Mundial de la Asociación Internacional de Derecho Constitucional (Oslo, Noruega, 16-20 de junio de 2014) con el título original "The Anti-Terrorist Fighting in Peru: Legal Black Holes, Grey Holes and the Arduous Constitutional Road. Peruvian Lessons for War against Global Terrorism», dentro del Workshop on Constitutional Responses to Terrorism.
} 
CONTENIDO: I. DOS MODELOS DE LUCHA ANTITERRORISTA RIVALES Y LA EVOLUCIÓN DEL TERRORISMO PERUANO.- II. MAL USO DEL RÉGIMEN DE EXCEPCIÓN CONSTITUCIONAL Y NORMALIZACIÓN DE LA EMERGENCIA.III. LEGISLACIÓN ANTITERRORISTA Y GRAVES VULNERACIONES DE DERECHOS FUNDAMENTALES: LA DESAPARICIÓN FORZADA DE PERSONAS.- IV. EL ROL DE LOS TRIBUNALES Y LA ARDUA AFIRMACIÓN DEL MODELO CONSTITUCIONAL Y DEMOCRÁTICO DE LUCHA ANTITERRORISTA.IV.1. INCONSTITUCIONALIDAD DE LA LEGISLACIÓN ANTITERRORISTA.IV.2.INCONSTITUCIONALIDADDELALEGISLACIÓNSOBRELAINTERVENCIÓN DE LAS FUERZAS ARMADAS DURANTE EL RÉGIMEN DE EXCEPCIÓN.IV.3. LA CONDENA AL EX PRESIDENTE FUJIMORI.-V. BIBLIOGRAFÍA.

\section{DOS MODELOS DE LUCHA ANTITERRORISTA RIVALES Y LA EVOLUCIÓN DEL TERRORISMO PERUANO}

El Perú padece acciones terroristas desde el año 1980, cuando «Sendero Luminoso», un grupo subversivo de orientación maoísta, inició la lucha armada para capturar el poder estatal con un simbólico acto de sabotaje electoral en Chuschi, un pueblito de Ayacucho, en los Andes peruanos (CVR, 2004, p. 97; Gorriti, 2009, pp. 43-44). Poco después, en 1984, el «Movimiento Revolucionario Túpac Amaru» (MRTA), de otra vertiente comunista (inspirada en las guerrillas clásicas latinoamericanas) pero con similares métodos violentos, abrió un nuevo flanco de acción insurgente y terrorista en el país (CVR, 2003, II, pp. 384-385, 387; Manrique, 2002, pp. 121, 46; Chiabra, 2009 , p. 343), aumentando la complejidad del desafío que enfrentaba la democracia peruana, recién restaurada tras doce años de régimen militar (1968-1980).

La ineficacia policial ante el rápido incremento de la violencia subversiva y el amplio uso de métodos terroristas que causaban pánico entre la ciudadanía determinó al Gobierno a poner en marcha una estrategia contra el terrorismo cualitativamente distinta al primer ensayo de respuesta, el cual se había apoyado básicamente en la labor policial bajo condiciones más o menos ordinarias. Los principales elementos de la nueva estrategia antiterrorista —una estrategia belicista o militarista - fueron los siguientes: el ejercicio de poderes de emergencia por el presidente de la República; la proclamación y el mantenimiento prolongado de un régimen de excepción constitucional; la militarización de la respuesta estatal y la abdicación de la autoridad democrática en las Fuerzas Armadas; la aprobación y aplicación de leyes antiterroristas violatorias de los derechos fundamentales de las personas; y la ausencia de controles parlamentarios y judiciales. 
La nueva estrategia fue una estrategia de «guerra contra el terrorismo» (CVR, 2003, II, pp. 247, 249 y 251; de la Jara, 2008, pp. 235, 239 y 240) y estuvo centrada en los poderes de emergencia constitucional ejercidos por el presidente de la República, quien los delegó de manera irrestricta en las Fuerzas Armadas, a las que encomendó derrotar militarmente a los movimientos terroristas. La sobrerreacción estatal llevó a la «guerra sucia» y a las graves violaciones de los derechos fundamentales, victimizando de modo especial a la población civil, la cual se halló así entre dos fuegos. Se respondió, pues, a la barbarie con la barbarie (de la Jara, 2008, pp. 240, 247). La crueldad del terrorismo fue replicada con atrocidades por las fuerzas del orden.

Los daños producidos por la guerra entre los años 1980 y 2000 han sido enormes. Según la Comisión de la Verdad y Reconciliación (CVR), que empleó la categoría de «conflicto armado interno», se trató del «episodio de violencia más intenso, más extenso y más prolongado de toda la historia de la República», y la cifra más probable de víctimas fatales es 69280 personas (CVR, 2003, VIII, p. 353). Además, la guerra abarcó una gran proporción del territorio nacional, causando grandes pérdidas económicas e involucrando al conjunto de la sociedad (CVR, 2003, VIII, pp. 353-354). Las principales víctimas fueron las poblaciones del Perú rural, andino y selvático, quechua y asháninka, campesino, pobre y con poca educación formal (CVR, 2003, VIII, p. 354), por lo que su tragedia no fue sentida como propia por el resto del país, lo que delata el velado racismo y desprecio hacia ellas que subsisten en el Perú hasta hoy (CVR, 2003, VIII; Lerner Febres, 2011, pp. 61 y $63-64)^{1}$.

En opinión de algunos analistas, el avance de la subversión terrorista, en particular de Sendero Luminoso, llegó a amenazar con derribar al régimen democrático, configurándose como un peligro existencial para la continuidad del Estado peruano o la comunidad nacional ${ }^{2}$. Una auténtica guerra civil pareció desencadenarse por momentos en el país, en particular durante los períodos que la CVR (CVR) llamó de «despliegue nacional de la violencia» (junio de 1986-marzo de 1989) y «crisis extrema: ofensiva subversiva y contraofensiva estatal» (marzo de 1989-septiembre de 1992) (CVR, 2004, pp. 109 y 113).

1 La respuesta al terrorismo global en Estados Unidos de América ha tenido también un perfil racial y étnico, de raíces históricas, que ha sido advertido por algunos autores. Véase Cole (2005, pp. 47-56).

2 En abril de 1992, el subsecretario de Estado para América Latina sostuvo ante la Cámara de Representantes de su país que los Estados Unidos de América debían contemplar la posibilidad de una intervención militar multinacional en el Perú, a fin de impedir el triunfo eventual de Sendero Luminoso, el cual podría acarrear el tercer genocidio del siglo, luego del perpetrado por la Alemania nazi y del cometido por el Khmer Rouge en Camboya. Véase Manrique (2002, pp. 62 y 227). También de la Jara opina que Sendero Luminoso estuvo a punto de ganar la guerra (2008, pp. 239, 240, 241, 243 (nota 7) y 249). 
Desde muy pronto, empero, surgió en el Perú un modelo constitucional y democrático de combate al terrorismo, con las siguientes características: conducción de la lucha antiterrorista por la autoridad civil democrática, de suerte que la eventual intervención de las Fuerzas Armadas se hallara siempre subordinada a aquella; legitimidad del recurso al régimen de excepción constitucional, pero sujeto a límites constitucionales y legales; respuesta estatal no exclusivamente militar, sino de naturaleza integral, que pudiera ganar la adhesión de las poblaciones aterrorizadas por Sendero Luminoso y el MRTA; aprobación y aplicación de legislación antiterrorista respetuosa de los derechos fundamentales de las personas; papel destacado del Parlamento y de los tribunales para ejercer controles democráticos y jurisdiccionales.

Tras un tímido intento de cambio para reconducir la estrategia antiterrorista bajo pautas constitucionales y democráticas, ocurrido al inicio del gobierno del presidente Alejandro Toledo (agosto de 2001-mayo de 2004) (Basombrío \& Rospigliosi, 2006, pp. 179-183), el presente siglo ha visto resurgir el modelo del militarismo -aunque atemperado- para enfrentar los remanentes terroristas que subsisten en dos zonas focalizadas de la Amazonía peruana: el valle del Alto Huallaga (VAH) y el valle de los ríos Apurímac, Ene y Mantaro (VRAEM) (Sánchez Montenegro, 2011, pp. 139-140; Soberón Garrido, 2013, p. 118). Las circunstancias actuales, sin embargo, son muy distintas de las que existieron durante las dos décadas finales del siglo pasado. No solo los remanentes de Sendero Luminoso (el MRTA ha dejado de operar desde hace varios años) no representan una amenaza existencial para el Estado peruano — debido al número limitado de sus militantes, a la precariedad de su fuerza militar, a su falta de consistencia ideológica y a su carencia de liderazgo político-, sino que han establecido una alianza estratégica con grupos dedicados al narcotráfico (Basombrío \& Rospigliosi, 2006, pp. 188-189 y 191; Chiabra, 2009, pp. 354-355; Agüero, 2009, pp. 60-63).

De cualquier modo, no parece fácil poner fin al fenómeno terrorista focalizado y débil que subsiste en el Perú. Los remanentes de Sendero Luminoso mantienen un discurso político subversivo (Chiabra, 2009, pp. 362-365; Agüero, 2009, p. 62) y realizan acciones armadas que siguen causando pérdida de vidas humanas y bienes materiales y provocando miedo y zozobra entre la ciudadanía, a nivel local y nacional (Defensoría del Pueblo, 2013, pp. 7 y 8). Con todo, en este nuevo escenario terrorista, la reintroducción y el mantenimiento de una estrategia antiterrorista basada en la prolongación de la emergencia constitucional y la militarización (atenuada) de la respuesta del Estado parecen, además de ineficaces, del todo injustificados desde el punto de vista constitucional. 


\section{MAL USO DEL RÉGIMEN DE EXCEPCIÓN CONSTI- TUCIONAL Y NORMALIZACIÓN DE LA EMERGENCIA}

En el Perú, el modelo constitucional de gobierno de crisis, de acuerdo con el marco conceptual propuesto por Oren Gross y Fionnuala Ní Aoláin, es el «modelo de la adaptación», conforme al cual «cuando una nación es confrontada con emergencias, su estructura legal, y aun constitucional, debe ser relajada en algo (y quizá incluso suspendida en partes)»(Gross \& Ní Aoláin, 2006, p. 17). Tanto la Constitución peruana en vigor desde 1993 como su antecesora de 1979 previeron un «régimen de excepción», con dos modalidades de respuesta estatal según la naturaleza y gravedad de la amenaza: el «estado de emergencia» para el caso de perturbación de la paz o del orden interno, catástrofe o graves circunstancias que afecten la vida de la nación, y el «estado de sitio» para supuestos de invasión, guerra exterior y guerra civil, o peligro inminente de que se produzcan. Ambas modalidades facultan al presidente a suspender el ejercicio de determinados derechos fundamentales y a ordenar la intervención de las Fuerzas Armadas para hacerse cargo del control del orden interno.

El que la estrategia de lucha antiterrorista incluyera como uno de sus componentes esenciales la instauración del «estado de emergencia» ha sido considerado como plenamente legítimo (CVR, 2003, VI, p. 494; de la Jara, 2003, p. 53), en particular, en aquellos momentos en los que el accionar de las organizaciones terroristas supuso una «amenaza existencial» para el Estado o la comunidad nacional ${ }^{3}$. Los problemas, más bien, derivaron de la manera en la que los poderes presidenciales de crisis fueron ejercidos y el régimen excepcional fue aplicado, pues ello conllevó una grave distorsión de principios fundamentales del orden constitucional, favoreciendo la comisión de graves violaciones de los derechos fundamentales de las personas (CVR, 2003, VI, 494-495; Lerner Febres, 2011, p. 60).

Una somera presentación de algunas cifras extraídas de una «Base de Datos sobre Estados de Emergencia en el Perú entre los años 1980 y 2011», elaborada en el marco de una investigación que actualmente desarrolla el autor de esta ponencia ${ }^{4}$, brinda una idea aproximada de la dimensión y las características de la problemática. En efecto, en los 32 años bajo estudio, se dictaron 866 decretos presidenciales de «estado de emergencia», casi todos los cuales proclamaron o prorrogaron sucesivamente el mencionado régimen excepcional $(839$ decretos, equivalentes al 96,9\%). De ese número, 672 decretos $(77,6 \%)$

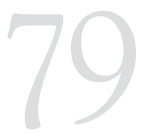

LA LUCHA ANTITERRORISTA EN EL PERÚ: AGUJEROS NEGROS LEGALES, AGUJEROS GRISES Y EL ARDUO CAMINO CONSTITUCIONAL. LECCIONES

PERUANAS PARA

LA GUERRA

CONTRA EL

TERRORISMO

GLOBAL

THE ANTI-

TERRORIST

FIGHTING IN

PERU: LEGAL

BLACK HOLES,

GRAY HOLES AND

THE ARDUOUS

CONSTITUTIONAL WAY. PERUVIAN LESSONS FOR THE WAR ON GLOBAL TERRORISM

3 Sobre el concepto de «amenaza existencial» como amenaza política al sistema constitucional o a la independencia de la República, o como peligro para la vida de la nación, véase Ackerman (2007, pp. 35, 36, 39, 82-83 y 87) y Pérez Royo (2010, p. 9).

4 Colaboraron en la tarea de diseñar la base de datos y recolectar y procesar la información, el ingeniero Javier Márquez y los alumnos Gonzalo Monge, Alonso Hidalgo, Joseline Pérez y Margarita Romero. 
corresponden a la causal de perturbación de la paz o del orden interno. Desde la aparición del desafío terrorista en 1980, en ningún año se ha prescindido del gobierno de crisis constitucional para hacerle frente.

De otro lado, la potestad presidencial de ordenar la intervención de las Fuerzas Armadas en el control del orden interno fue ampliamente utilizada. Así, las Fuerzas Armadas intervienen en más de dos tercios de los casos (603 decretos, iguales al 69,6\%). Además, la modalidad de intervención es casi siempre la que les encomienda tomar por completo el control del orden interno, en reemplazo de la Policía (548 casos, equivalentes al 90,9\%). Por lo que se refiere a los derechos fundamentales, los casos en los que el presidente determinó su suspensión fueron 635 (equivalentes al 73,3\%). Por último, respecto de la duración prevista - considerando solo aquellos decretos que instauran o prorrogan el estado de emergencia (839 decretos)_, la gran mayoría estipuló el máximo constitucional de 60 días (722 decretos, que corresponden al $86,1 \%$ del subconjunto).

En definitiva, las cifras muestran que el régimen de excepción, como parte esencial de la estrategia antiterrorista aplicada, ha devenido en permanente en el Perú, pues se lo mantiene en vastos sectores del territorio nacional y para importantes grupos poblacionales, durante los 32 años estudiados ${ }^{5}$. Con ello, se lo ha convertido en práctica ordinaria, contraviniendo el carácter provisorio de la institución ${ }^{6}$ y produciendo la «normalización de la emergencia» (sobre este concepto, véase Ackerman, 2007, p. 70; Gross \& Ní Aoláin, 2006, pp. 228ss; de Vergottini, 2004, p. 23; Dyzenhaus, 2002, pp. 28-29), lo que distorsiona gravemente el Estado constitucional y democrático de Derecho.

Por lo demás, resulta claro que el empleo del «estado de emergencia» ha supuesto la aplicación del máximo de severidad que la Constitución habilita: renovación incesante del estado de emergencia, por hechos vinculados a la causal de perturbación de la paz o del orden interno, durante el mayor tiempo permitido, con suspensión de derechos fundamentales, y con intervención de las Fuerzas Armadas, en sustitución de la Policía, para hacerse cargo del control del orden interno.

Ahora bien, este modo de entender el régimen de excepción y de aplicarlo era portador de una serie de rasgos autoritarios y antidemocráticos, así como violatorio del Estado constitucional de derecho. Y es que, desde que el presidente Fernando Belaunde, en diciembre de 1982, reinstauró el estado de emergencia en Ayacucho y encargó el combate del terrorismo a las Fuerzas Armadas, se reintrodujo la figura, no contemplada en la

5 Sobre la recurrencia de los regímenes de excepción en la historia constitucional peruana, véase Landa Arroyo (2012, p. 220).

6 Los requisitos de necesidad y temporalidad son señalados como esenciales desde los autores clásicos. Véase Rossiter (2011, pp. 300, 303 y 306; Friedrich, 1975, II, pp. 589-590). 
Constitución sino heredada del régimen castrense anterior (1968-1980), de los «Comandos Político-Militares» a cargo de un jefe militar (CVR, 2003, VI, p. 497; Manrique, 2002, p. 15)?

El otorgamiento de poderes políticos a las Fuerzas Armadas excedía los cauces constitucionales y careció de apoyo legislativo hasta junio de 1985, cuando el Parlamento aprobó la ley 24150, la cual reguló las imprecisas competencias de los Comandos Político-Militares durante los estados de excepción, convalidando su rol inconstitucional. Unos años más tarde, la situación normativa empeoró. Las atribuciones desmesuradas de los Comandos Político-Militares fueron ampliadas mediante el decreto legislativo 749, de noviembre de 1991, dictado por el Gobierno en virtud de una delegación expresa de potestades legislativas por el Parlamento.

De otro lado, la ley 23506, de diciembre de 1982, contra lo establecido por la Convención Americana sobre Derechos Humanos (CADH) - confirmado unos años más tarde por la Corte Interamericana de Derechos Humanos (Corte IDH, 1987a; 1987b)_, estipuló la improcedencia de las demandas de hábeas corpus y amparo respecto de las garantías o derechos cuya suspensión hubiese sido dispuesta al declarar o prorrogar un estado de excepción constitucional. Ello llevó a los fiscales y jueces peruanos, sobre la base de una interpretación errónea de la Constitución y del desconocimiento del Derecho Internacional de los Derechos Humanos (DIDH), a rechazar mayoritariamente las numerosas demandas de hábeas corpus y amparo presentadas por los allegados de las víctimas de las graves violaciones de los derechos fundamentales causadas por la represión estatal (CVR, 2003, VI, pp. 511-512; Eguiguren Praeli, 2002, pp. 54-58).

Fueron creadas así las condiciones para un ejercicio abusivo de los poderes de emergencia, al «abdicar la autoridad democrática» y delegar indebidamente en las Fuerzas Armadas la conducción de la «guerra contra el terrorismo» (CVR, 2003, VIII, pp. 364-366; Lerner Febres, 2011, p. 60), no poner en vigor ni ejercer mecanismos de control sobre dichos poderes de emergencia, y, por el contrario, aprobar legislación que, contra los principios recogidos en la Constitución y el $\mathrm{DIDH}$, impedía brindar adecuada protección judicial a los derechos fundamentales de las personas. De ese modo, se configuró un «agujero negro legal», entendido, según lo que plantea David Dyzenhaus, como una situación creada por la ley, en particular para personas sujetas

7 En realidad, la concesión de amplios poderes «políticos y militares» a un caudillo militar para enfrentar emergencias políticas, en particular situaciones bélicas o conflictos armados, se remonta en el Perú hasta el mismo momento fundacional de la República, con los poderes reconocidos al Protector José de San Martín en 1821 y al Libertador Simón Bolívar entre 1823 y 1825 . Me ocupo del tema en un trabajo en elaboración titulado El Derecho Constitucional peruano frente a las emergencias provocadas por la violencia política (pp. 26-29).

LA LUCHA ANTITERRORISTA EN EL PERÚ: AGUJEROS NEGROS LEGALES, AGUJEROS GRISES Y EL ARDUO CAMINO CONSTITUCIONAL. LECCIONES

PERUANAS PARA

LA GUERRA

CONTRA EL TERRORISMO GLOBAL

THE ANTITERRORIST FIGHTING IN PERU: LEGAL BLACK HOLES, GRAY HOLES AND THE ARDUOUS CONSTITUTIONAL WAY. PERUVIAN LESSONS FOR THE WAR ON GLOBAL TERRORISM 
a detención administrativa o prejudicial, en la cual «no hay Derecho» o se impide la revisión judicial, o que «no puede ser controlada por el Estado de Derecho», o que «es inmune a una revisión por una corte o un fuero independiente» (Dyzenhaus, 2006, pp. 3, 123 y 166) ${ }^{8}$.

Pero no solo durante las dos primeras décadas de terrorismo en el Perú (1980-2000), cuando este fenómeno llegó a agobiar a la sociedad peruana como un decisivo asunto de supervivencia, los estados de excepción han sido manipulados y su propósito y sus características constitucionales distorsionados de manera grave. Incluso en el presente siglo, cuando el accionar terrorista se halla focalizado en dos zonas de la selva y no constituye una amenaza existencial para el Estado o la nación, se lo sigue empleando (ONU, 2010, párrafo 31; el relator especial constata la continuidad de la práctica de declarar el estado de emergencia en el VRAE). Desde luego, la principal distorsión consiste ahora en que no se configura ninguna causal constitucional que habilite la proclamación del régimen excepcional.

Aunque en la retórica oficial del Estado se recurre a la expresión «guerra contra el terrorismo» para justificar el mantenimiento del estado de emergencia y la participación preeminente de las Fuerzas Armadas en el combate contra los rezagos senderistas en el VRAEM ${ }^{9}$, tal uso resulta excesivo e inadmisible desde el punto de vista del derecho constitucional peruano. No existe en la actualidad una situación bélica ni de insurgencia, ni un accionar terrorista que constituyan una amenaza existencial para el Estado o la nación, ni siquiera debido a la alianza de Sendero Luminoso con narcotraficantes.

Más bien, el empleo de la retórica belicista parece servir a las Fuerzas Armadas, pese a sus numerosos fracasos operativos, para el desmedido incremento de su poder en la sociedad y para su propósito de recuperación institucional (Sánchez Montenegro, 2011, pp. 101, 114-119 y 142-143) tras su involucramiento en la red de corrupción y violación de derechos fundamentales durante el gobierno autoritario del presidente Fujimori (CVR, 2003, II, p. 376; Durand, 2003, pp. 421ss.). Salvadas las distancias, parece estar ocurriendo en el Perú algo parecido a lo que observa Mark Brandon para el caso de Estados Unidos de América, y es que se constituye como un «Estado guerrero», esto es, como «un régimen para el cual el uso de la fuerza militar es un aspecto regular de la vida de la nación» $(2006$, p. 12).

Como se sabe, la manipulación del concepto de guerra — guerra interna, en el caso peruano- conlleva serios peligros para la democracia

8 Para una referencia al uso del concepto «agujero negro legal» en el caso Abbasi, decidido por una corte británica, véase Cole (2005, p. 40).

9 Mediante decreto supremo 074-2012-PCM (Presidencia del Consejo de Ministros, 2012), se convirtió el VRAE en VRAEM, al agregársele nuevos territorios de la zona del río Mantaro. 
constitucional, como el uso abusivo de los poderes presidenciales de excepción, la violación de los derechos fundamentales de los sospechosos de terrorismo y el debilitamiento de los controles jurisdiccionales y parlamentarios, con la ulterior erosión permanente del Estado de Derecho y el régimen constitucional (Ackerman, 2007, pp. 25-29).

\section{LEGISLACIÓN ANTITERRORISTA Y GRAVES VULNERACIONES DE DERECHOS FUNDAMENTALES: LA DESAPARICIÓN FORZADA DE PERSONAS}

La aprobación de «legislación penal de emergencia» (CVR, 2003, VI, pp. 421 y 422; Landa, 2006, p. 94; Ugaz Sánchez-Moreno, 1996, p. 55) para hacer frente al terrorismo en el Perú, desde el temprano decreto legislativo 46, de marzo de 1981, hasta los draconianos decretos ley antiterroristas puestos en vigor por el presidente Alberto Fujimori tras su autogolpe de Estado del 5 de abril de 1992, produjo una profunda alteración del Estado constitucional y democrático de derecho. Como ha señalado la CVR, las leyes antiterroristas causaron «un desborde permanente del modelo garantista» y generaron «una cultura de la emergencia y una práctica de la excepción como regla», originando una involución del derecho penal peruano hasta estándares pre-modernos (CVR, 2003, VI, p. 422; Ugaz Sánchez-Moreno, 1996, pp. 55-56).

Las leyes penales de emergencia incurrieron en numerosas violaciones de los derechos fundamentales de las personas: tipificación imprecisa de los delitos de «terrorismo» y «traición a la patria»; violación de las libertades de pensamiento y expresión mediante la tipificación del delito de «apología del terrorismo»; ampliación indebida de los poderes de investigación criminal concedidos a la Policía, sustraídos en la práctica a controles por fiscales y jueces; potestad de mantener en situación de incomunicación bajo detención preventiva (administrativa) a los sospechosos de terrorismo, sin debidos controles fiscales y jurisdiccionales; facilitación de la detención fuera de los supuestos de flagrancia y orden judicial previstos en la Constitución, y por plazos excesivos; facilitación de la realización de arrestos y aun actuaciones probatorias por las Fuerzas Armadas en las zonas declaradas bajo estado de excepción constitucional; juzgamiento por jueces «sin rostro»; juzgamiento de civiles ante tribunales militares; aplicación del proceso militar «en el teatro de operaciones» (escenario bélico), con plazos exiguos (CVR, 2003, VI, pp. 425-463; CIDH, 2000, especialmente el capítulo II, párrafos 1-254; Ugaz Sánchez-Moreno, 1996, p. 55; Comisión Goldman, 1994, pp. 45-78).

Cabe detenerse, empero, a modo de ilustración, en una de las peores prácticas de violaciones masivas de los derechos fundamentales de las personas cometidas durante la guerra contra el terrorismo en

LA LUCHA ANTITERRORISTA EN EL PERÚ: AGUJEROS NEGROS LEGALES, AGUJEROS GRISES Y EL ARDUO CAMINO CONSTITUCIONAL. LECCIONES

PERUANAS PARA

LA GUERRA

CONTRA EL

TERRORISMO

GLOBAL

THE ANTI-

TERRORIST

FIGHTING IN

PERU: LEGAL

BLACK HOLES,

GRAY HOLES AND

THE ARDUOUS

CONSTITUTIONAL WAY. PERUVIAN LESSONS FORTHE WAR ON GLOBAL

TERRORISM 
el Perú, a saber, la práctica de la detención arbitraria (administrativa) y la posterior desaparición forzada de los sospechosos de terrorismo, con el probable resultado de su ejecución extrajudicial (CVR, 2003, VI, pp. 111 y 122; Defensoría del Pueblo, 2002, p. 143). La legislación penal de emergencia, y su aplicación por el sistema de justicia conforme a criterios laxos que omitieron todo control de constitucionalidad, favoreció la perpetración de los crímenes.

Según la CVR, las Fuerzas Armadas recurrieron a la desaparición forzada de personas con la finalidad de derrotar militarmente a las organizaciones subversivas y terroristas, y procuraron como objetivos inmediatos los siguientes: obtener información de los sospechosos; eliminar a los presuntos subversivos o simpatizantes; y, en ciertos períodos, intimidar a la población y obligarla a ponerse del lado del Estado en los territorios declarados bajo régimen de emergencia (CVR, 2003, VI, p. 131). Por otra parte, se trató de una práctica generalizada y sistemática en ciertos períodos y lugares, en particular, entre los años 1983 y 1984 o 1985, y entre los años 1989 y 1993 (CVR, 2003, VI, pp. 126-128; de la Jara, 2003, p. 58). Las cifras registradas dan cuenta de la barbarie, pues fluctúan entre 8558 y 15731 los casos estimados de víctimas de desaparición forzada (Defensoría del Pueblo, 2013, pp. 148-149).

La CVR y la Corte IDH han calificado los hechos del caso La Cantuta - donde nueve estudiantes universitarios y un catedrático fueron desaparecidos y asesinados, con el posterior ocultamiento de sus cadáveres- como «crímenes de lesa humanidad» (CVR, 2003, VI, p. 129; Corte IDH, 2006, párrafo 225). Y es que nada parece igualar a la experiencia de desvalimiento y falta de protección legal en que son colocadas las víctimas de desaparición forzada (Cassese, 1993, pp. 186-191; CVR, 2003, VI, pp. 96-112; Defensoría del Pueblo, 2002, pp. 114-125). En consecuencia, de los desaparecidos puede decirse, en el sentido más radical, que se hallan en un auténtico «agujero negro», en la medida en que se encuentran en una situación de desprotección jurídica total, sin que ni siquiera su arresto y detención sean reconocidos, ni aun su misma personalidad jurídica.

En efecto, por constituir la desaparición forzada de personas un hecho pluriofensivo (CVR, 2003, VI, pp. 75-76 y 130; Abad Yupanqui, 2004, pp. 120-121), la creación de «agujeros negros» $\mathrm{y}$ «agujeros grises» legales en torno a ella, como consecuencia de la legislación antiterrorista aprobada y del rol desempeñado por el sistema de justicia para asegurar la impunidad de los perpetradores (CVR, 2003, III, pp. 258-261 y 276-279; de la Jara, 2003, pp. 52-60), es algo que hay que deplorar y cuya repetición, en el Perú y en cualquier otro país, debe ser evitada por todos los medios moral y jurídicamente admisibles. 
Algunas de estas leyes y actuaciones jurisdiccionales configuraron «agujeros grises legales», ya que adoptaron una careta de legalidad, esto es, usurparon la legitimidad del Estado constitucional y democrático de derecho, pero negaron toda protección sustantiva. Para David Dyzenhaus, los «agujeros grises legales» son «agujeros negros disfrazados» y solo brindan la «fachada o forma del Estado de derecho», siendo «más peligrosos» que los mismos agujeros negros, ya que encubren su falta de sustancia y configuran espacios que no son adecuadamente controlados por la legalidad (por ejemplo, los tribunales militares estadunidenses tras el 11 de septiembre de 2001). En consecuencia, Dyzenhaus opina que los tribunales de justicia deben evitar convertirse en meros órganos limitados a «rubricar» las decisiones del Ejecutivo (2006, pp. 3, 42, 50, 205 y 210).

En la experiencia peruana, un ejemplo extremo de este fenómeno lo constituye lo ocurrido en los casos de la matanza de Barrios Altos y las desapariciones forzadas de La Cantuta; ambos, crímenes atroces perpetrados por el escuadrón de aniquilamiento estatal denominado «Grupo Colina», en 1991 y 1992. Y es que el Grupo Colina, que actuaba en el marco de la estrategia militarista de lucha contra el terrorismo, fue sometido a un relativamente temprano encausamiento penal en el fuero ordinario, durante el año 1995, por las ejecuciones extrajudiciales cometidas en el caso Barrios Altos. Reaccionando a la persecución penal y para sellar una política estatal de impunidad, el Congreso, de mayoría gobiernista, aprobó entonces una inconstitucional ley de amnistía por los delitos contra los derechos fundamentales cometidos en la lucha antiterrorista (ley 26479 de junio de 1995). No obstante, la jueza que instruía la causa, en una decisión de inusual integridad y valentía, declaró inaplicable la ley de «autoamnistía» al proceso penal por el caso Barrios Altos, ejerciendo su potestad de control difuso de constitucionalidad. Ante ello, el Parlamento aprobó una nueva ley que prohibía la revisión judicial de la ley de amnistía (ley 26492 de julio de 1995). En un fallo vergonzoso, la Corte Suprema confirmó la revocación del control difuso de constitucionalidad aplicado por la jueza y avaló las leyes de «autoamnistía», sometiéndose a la política de impunidad del Gobierno y su mayoría parlamentaria (CVR, 2003, III, 161-164; VII, pp. 485-503 y 626-639; Defensoría del Pueblo, 2001).

El remedio a esta situación de impunidad solo llegaría años más tarde, cuando la Corte IDH dictó las sentencias de los casos Barrios Altos (2001) y La Cantuta (2006), declarando que las leyes de autoamnistía peruanas carecían de efectos jurídicos, por resultar incompatibles con la CADH (Corte IDH, 2001, punto resolutivo 4; 2006, punto resolutivo 7). Poco antes, en septiembre del año 2000, el presidente Fujimori se había visto obligado a anunciar la interrupción de su tercer mandato, obtenido en un proceso electoral fraudulento, al verse envuelto en una

LA LUCHA ANTI-

TERRORISTA EN EL PERÚ: AGUJEROS

NEGROS LEGALES,

AGUJEROS

GRISES Y EL

ARDUO CAMINO

CONSTITUCIONAL.

LECCIONES

PERUANAS PARA

LA GUERRA

CONTRA EL

TERRORISMO

GLOBAL

THE ANTI-

TERRORIST

FIGHTING IN

PERU: LEGAL

BLACK HOLES,

GRAY HOLES AND

THE ARDUOUS

CONSTITUTIONAL WAY. PERUVIAN

LESSONS FOR THE WAR ON GLOBAL

TERRORISM 
gran escándalo de corrupción (Murakami, 2012, pp. 517-537 y 550-562; Burt, 2009, pp. 345-351 y 386-390). Tras la primera sentencia de la Corte IDH, los tribunales nacionales reabrieron los procesos penales que habían sido sobreseídos en aplicación de las aberrantes leyes de autoamnistía (Defensoría del Pueblo, 2005, pp. 115-129 y 314).

\section{IV.EL ROL DE LOS TRIBUNALES Y LA ARDUA AFIRMACIÓN DEL MODELO CONSTITUCIONAL Y DEMOCRÁTICO DE LUCHA ANTITERRORISTA ${ }^{10}$}

\section{IV.1.Inconstitucionalidad de la legislación antiterrorista}

David Dyzenhaus asevera que el ordenamiento jurídico contiene un «proyecto de Estado de derecho» (un «ideal al cual se aspira»), a cuya realización están llamados a contribuir no solo los jueces, sino también la Legislatura y el Ejecutivo (2006, pp. 3, 7, 8, 147, 150, 195-196 y 211). Eso es, precisamente, lo que ha ocurrido en el caso peruano con ocasión de la expedición de la sentencia del Tribunal Constitucional sobre la inconstitucionalidad de la legislación antiterrorista, en enero de 2003.

El problema que se arrastraba, por cierto, era el de los numerosos juicios penales contra sospechosos de terrorismo, sustanciados tanto en el fuero civil como en el fuero militar, en aplicación de la legislación penal de emergencia, completamente reñida con los estándares constitucionales y del DIDH. Inclusive, la aplicación de las leyes antiterroristas, en especial de las aprobadas durante el régimen del presidente Fujimori, produjo una gran cantidad de inocentes condenados de manera injusta (CVR, 2003, VI, pp. 463-471; Comisión Ad-Hoc a favor de los Inocentes en Prisión, 2000; de la Jara, 2001).

Ante la demanda de inconstitucionalidad interpuesta por la Defensoría del Pueblo, el Tribunal Constitucional, liberado ya de ataduras políticas, emitió una sentencia declarando la inconstitucionalidad parcial de la legislación antiterrorista (Tribunal Constitucional, 2003). La decisión jurisdiccional declaró que las leyes antiterroristas impugnadas eran parcialmente inconstitucionales y estableció una serie de criterios interpretativos vinculantes, a fin de reconducir dentro del marco constitucional determinadas disposiciones legales.

Así, entre los principales contenidos de la sentencia figuran los siguientes: el establecimiento de los criterios interpretativos a observar por los jueces respecto de la tipificación del delito de «terrorismo», a

10 Con todo lo importante que son las sentencias que se comentan en este acápite, debe lamentarse que llegaran tarde para impedir o aminorar el vaciamiento del Estado constitucional de derecho y la vulneración de los derechos fundamentales durante la peor época. Sobre la idea de "ciclos judiciales" relacionados con las emergencias en Estados Unidos de América, con una etapa «permisiva» y otra «revisionista», véase Ackerman (2007, pp. 87-91 y Tushnet (2006, pp. 127 y 134-136). 
fin de reducir sus indeterminaciones y no colisionar con el principio constitucional de legalidad ${ }^{11}$; la declaración de inconstitucionalidad del delito de «traición a la patria» y del delito de «apología del terrorismo»; la declaración de inconstitucionalidad de los procesos penales realizados ante tribunales militares; las interpretaciones correctas, desde el punto de vista del derecho constitucional, de la regulación legal sobre la potestad jurisdiccional de expedir mandatos de prisión preventiva y del derecho de los detenidos a no ser incomunicados sino en casos indispensables; la declaración de que la sentencia no generaba derechos de excarcelación para los procesados y condenados por la aplicación de las normas juzgadas inconstitucionales por el fallo (Tribunal Constitucional, 2003; Landa Arroyo, 2006, pp. 95-105; Francia, 2006, pp. 141-142).

Al fundamentar la decisión, el Tribunal Constitucional se ciñó a diversos criterios jurisprudenciales fijados por la Corte IDH en varias sentencias emitidas en casos seguidos contra el Estado peruano (en los fundamentos jurídicos 39, 98, 100, 129 y 155 remite a Corte IDH, 1999; en el fundamento jurídico 99, a Corte IDH, 2000; en el fundamento jurídico 219, a Corte IDH, 1997a) y contra otros Estados (en el fundamento jurídico 172 remite a Corte IDH, 1997b), así como en sus opiniones consultivas (en el fundamento jurídico 181 remite a Corte IDH, 1994). Con ello, se produjo un enriquecedor proceso de diálogo interjurisdiccional sostenido entre la justicia constitucional peruana y el máximo tribunal de las Américas en materia de protección internacional de derechos humanos.

De otro lado, la sentencia del Tribunal Constitucional cuidó, asimismo, de no generar consecuencias negativas por la aplicación inmediata de su fallo. En tal sentido, decretó un período de vacatio sententiae, durante el cual ella aún no surtiría efectos, y exhortó al Congreso de la República a legislar entre tanto sobre las materias examinadas, conforme a lo decidido por el supremo intérprete de la Constitución, de suerte que no se produjeran vacíos o lagunas del derecho que pudieran perjudicar la política penal y penitenciaria del Estado. El Parlamento, por su parte, aprobó una ley de delegación de potestades legislativas al Gobierno. Poco después (entre enero y febrero de 2003), los decretos legislativos de reforma de la legislación antiterrorista fueron puestos en vigor, permitiendo la revisión de los procesos penales inconstitucionales y su adaptación a la Constitución y el DIDH.

Así, se produjo un interesante proceso de cooperación entre poderes públicos, dirigido tanto al establecimiento de un modelo normativo de

11 No obstante, el relator especial de la ONU ha llamado la atención acerca del mantenimiento de disposiciones de carácter abierto, que contravienen el principio de legalidad, en la legislación antiterrorista peruana aun después del fallo del Tribunal Constitucional en esta causa (ONU, 2010, párrafos 21, 24 y 44).

LA LUCHA ANTITERRORISTA EN EL PERÚ: AGUJEROS NEGROS LEGALES, AGUJEROS GRISES Y EL ARDUO CAMINO CONSTITUCIONAL. LECCIONES

PERUANAS PARA

LA GUERRA

CONTRA EL

TERRORISMO

GLOBAL

THE ANTI-

TERRORIST

FIGHTING IN

PERU: LEGAL

BLACK HOLES,

GRAY HOLES AND

THE ARDUOUS

CONSTITUTIONAL WAY. PERUVIAN LESSONS FORTHE WAR ON GLOBAL TERRORISM 
lucha antiterrorista respetuoso de la Constitución, como a la corrección de las peores medidas violatorias de los derechos fundamentales de los sospechosos de terrorismo.

\section{IV.2. Inconstitucionalidad de la legislación sobre la intervención de las Fuerzas Armadas durante el régimen de excepción}

Con ocasión de una demanda de inconstitucionalidad presentada por la Defensoría del Pueblo contra la ley 24150 y el decreto legislativo 749 , el Tribunal Constitucional ha anulado diversas disposiciones legales que vulneraban de modo flagrante el marco constitucional y el DIDH, al atribuir funciones excesivas y carentes de control a las Fuerzas Armadas durante el régimen de excepción, así como al otorgarles blindaje legal y limitar severamente la responsabilidad por sus actos (Tribunal Constitucional, 2004).

Entre los principales contenidos de la sentencia se hallan los siguientes: la declaración de la inconstitucionalidad de los «Comandos PolíticoMilitares», señalando que en ningún caso las Fuerzas Armadas pueden ejercerfuncionespolíticas, debidoasucarácter «nodeliberante» estipulado por la Constitución; la nulidad de las disposiciones que permitían a los Comandos Político-Militares la conducción de acciones de desarrollo, sojuzgando a las autoridades políticas de organismos públicos y de gobiernos regionales y locales; la declaración de inconstitucionalidad de la potestad militar de reemplazar a las autoridades civiles en el territorio bajo régimen de excepción; la declaración de nulidad de la cláusula legal que extendía el fuero militar a actos ajenos al cumplimiento de funciones militares en las zonas declaradas bajo régimen de excepción (en la práctica, un mecanismo de impunidad).

Lamentablemente, la sentencia no abordó la cuestión de las renovaciones continuas del estado de emergencia en el Perú, que traen como consecuencia el surgimiento del fenómeno de la «permanencia de lo excepcional» o «normalización de la emergencia». Si bien en esta resolución el Tribunal Constitucional no exhortó al Parlamento a legislar de manera integral sobre los regímenes de excepción, una petición que sí había hecho la CVR en su Informe Final (2003, VI, p. 522), incluyó esta exhortación en una sentencia posterior (de septiembre de 2009), en la que declaró la inconstitucionalidad parcial de la legislación regulatoria del empleo de la fuerza por las Fuerzas Armadas en el territorio nacional y se pronunció sobre diversos aspectos relacionados con la intervención de las Fuerzas Armadas en tareas de control del orden interno, mediara o no la declaración de un régimen de excepción constitucional (Tribunal Constitucional, 2009, fundamento jurídico 31 y punto resolutivo 6). 
Esta última sentencia, sin embargo, tiende a favorecer la ampliación del rol de las Fuerzas Armadas en las funciones de control del orden interno, inclusive frente a eventuales manifestaciones de «protesta social» y aunque no mediara la instauración del régimen de excepción, lo que resulta incompatible con la Constitución (ONU, 2010, párrafos 34, 37 y 47; Pérez Aguilar, 2012, pp. 17-25). Es claro, entonces, que el proceso de afirmación del modelo constitucional y democrático de lucha antiterrorista muestra nuevamente en este episodio las dificultades que lo caracterizan.

\section{IV.3. La condena al expresidente Fujimori}

También la judicatura ordinaria ha ayudado a apuntalar el modelo democrático y constitucional de lucha contra el terrorismo en el Perú. Además de distintos casos de graves violaciones de los derechos fundamentales de las personas seguidos contra miembros de las fuerzas del orden, los cuales han sido judicializados con suerte diversa -en general, se observa retraso y dificultades en los procesos (Defensoría del Pueblo, 2013, pp. 123-146; Cáceres Valdivia, 2014, pp. 30-33)—, el caso más relevante es el que atañe al expresidente Alberto Fujimori. El ex mandatario de la nación, en efecto, ha recibido una condena a veinticinco años de prisión efectiva por parte de la Sala Penal Especial de la Corte Suprema de Justicia que lo juzgó, en abril de 2009 (Sala Penal Especial de la Corte Suprema de Justicia, 2009). La decisión fue confirmada en segunda instancia por la Primera Sala Penal Transitoria del máximo tribunal de la jurisdicción común, en diciembre de aquel mismo año (Primera Sala Penal Transitoria de la Corte Suprema de Justicia, 2009).

Ambas sentencias consideraron probada la responsabilidad de Fujimori en la comisión de homicidio calificado en agravio de veinticinco personas y de lesiones graves contra cuatro víctimas, en los casos de la matanza de Barrios Altos y las desapariciones forzadas y posteriores ejecuciones extrajudiciales de La Cantuta, así como en la comisión de secuestro agravado de dos personas en el caso de los Sótanos del Servicio de Inteligencia del Ejército (SIE). La responsabilidad penal de Fujimori estuvo fundamentada en su papel como «autor mediato» de un aparato de poder organizado al interior del Estado peruano, con la finalidad de perpetrar crímenes atroces, como parte de la lucha antiterrorista, a través del escuadrón de aniquilamiento conocido como «Grupo Colina». Tal responsabilidad, además, no se basó en prueba incriminatoria directa, sino en una serie de indicios que los jueces consideraron suficientes en número, coherencia y verosimilitud.

Interesa destacar aquí que el enjuiciamiento y la posterior condena fueron posibles gracias a un proceso de extradición que finalmente resolvió, a favor de realizar el proceso penal, la Corte Suprema de

LA LUCHA ANTITERRORISTA EN EL PERÚ: AGUJEROS NEGROS LEGALES, AGUJEROS GRISES Y EL ARDUO CAMINO CONSTITUCIONAL. LECCIONES

PERUANAS PARA

LA GUERRA

CONTRA EL

TERRORISMO

GLOBAL

THE ANTI-

TERRORIST

FIGHTING IN

PERU: LEGAL

BLACK HOLES,

GRAY HOLES AND

THE ARDUOUS

CONSTITUTIONAL

WAY. PERUVIAN

LESSONS FOR THE WAR ON GLOBAL

TERRORISM 
Chile, país adonde Fujimori había arribado en su viaje de regreso al Perú (Ambos, 2010, pp. 57-61; Román, 2009, pp. 117-143). Poco antes había dejado, por razones desconocidas, la protección legal de que gozaba en Japón, país del que Fujimori es también nacional, desde que se refugiara allí cuando el Parlamento declaró su vacancia en el cargo de presidente de la República por «incapacidad moral» (noviembre de 2000).

Las sentencias condenatorias de Fujimoripor los crímenes de Barrios Altos y La Cantuta, que las dos Salas de la Corte Suprema que intervinieron calificaron de «crímenes de lesa humanidad» (Sala Penal Especial de la Corte Suprema de Justicia, 2009, párrafos 653, 675 y 717; Primera Sala Penal Transitoria de la Corte Suprema de Justicia, 2009, p. 110) —como antes lo había hecho la Corte IDH (según se indicó en el acápite III de esta ponencia)—, han sido celebradas por importantes analistas como «históricas» (véase Ambos, 2010, p. 87; Meini, 2010, p. 213; Lerner Febres, 2011, pp. 66-68). No obstante, estudiosos igualmente serios han formulado dudas acerca del examen particularizado de cada uno de los requisitos exigibles en el marco de la teoría del autor mediato referida antes, y han observado que la «extrema concisión» de la primera sentencia en este punto "puede llegar a considerarse, incluso, como un supuesto de motivación defectuosa o insuficiente» (García Cavero, 2010, p. 209).

Como quiera que fuere, analizado el juicio y condena del expresidente Fujimori desde el punto de vista de los esfuerzos por afirmar una perspectiva constitucional y democrática de lucha antiterrorista, es claro el mensaje enviado por el sistema de justicia peruano. En efecto, con su eficaz recurso a la cooperación y la jurisprudencia internacionales -participación de las autoridades chilenas en el proceso de extradición y rol relevante de la Corte IDH en el establecimiento de estándares jurídicos, en especial, en los casos Barrios Altos y La Cantuta-, Perú muestra ante la comunidad de Estados constitucionales que la perpetración de graves violaciones de los derechos fundamentales de las personas y aun de «crímenes de lesa humanidad», como parte de una estrategia de guerra contra el terrorismo que quebrante los principios básicos del Estado constitucional, no ha de quedar impune.

\section{BIBLIOGRAFÍA}

Abad Yupanqui, Samuel (2004). Derecho procesal constitucional. Lima: Gaceta Jurídica.

Ackerman, Bruce (2007). Antes de que nos ataquen de nuevo: la defensa de las libertades en tiempo de terrorismo. Barcelona: Península.

Agüero, José Carlos (2009). Situación de derechos humanos en la zona del VRAE-Vizcatán. En Coordinadora Nacional de Derechos Humanos, Informe anual 2008. El difícil camino hacia la ciudadanía. Lima. 
Ambos, Kai (2010). Trasfondos políticos y jurídicos de la sentencia contra el ex Presidente peruano Alberto Fujimori. En Kai Ambos \& Iván Meini (eds.), La autoría mediata: el caso Fujimori. Lima: Ara.

Basombrío, Carlos \& Fernando Rospigliosi (2006). La seguridad y sus instituciones en el Perú a inicios del siglo XXI: reformas democráticas o neomilitarismo. Lima: IEP.

Brandon, Mark (2006). War and the American Constitutional Order. En Mark Tushnet (ed.), The Constitution in Wartime: Beyond Alarmism and Complacency. Durham/Londres: Duke University Press.

Burt, Jo-Marie. Violencia y autoritarismo en el Perú: bajo la sombra de Sendero y la dictadura de Fujimori. Lima: SER/IEP.

Cáceres Valdivia, Eduardo (2014). Renovar el compromiso con la memoria y la justicia. En Coordinadora Nacional de Derechos Humanos, Informe Anual 2012-2013: Diez años del Informe Final de la CVR. Lima.

Cassese, Antonio (1993). Los derechos humanos en el mundo contemporáneo. Barcelona: Ariel.

Chiabra, Roberto (2009). La seguridad nacional en el siglo XXI: políticas y estrategias. Lima: UIGV.

Cole, David (2005). Enemy Aliens: Double Standards and Constitutional Freedoms in the War on Terrorism. Nueva York: The New Press.

Comisión Ad-Hoc a favor de los Inocentes en Prisión (2000). La labor de la Comisión Ad-Hoc a favor de los Inocentes en Prisión. Logros y perspectivas (agosto de 1996-diciembre de 1999). Comisión creada por ley 26655. Lima: Defensoría del Pueblo.

Comisión de Juristas Internacionales (Comisión Goldman) (1994). Informe sobre la administración de justicia en el Perú. Lima: IDL.

Comisión de la Verdad y Reconciliación (CVR) (2003). Informe final. 9 volúmenes. Lima: CVR.

Comisión de la Verdad y Reconciliación (CVR) (2004). Informe final. Tomo I. Lima: UNSM/PUCP.

Comisión Interamericana de Derechos Humanos (CIDH) (2000). Segundo informe sobre la situación de los derechos humanos en el Perú. Washington D.C.

Corte Interamericana de Derechos Humanos (Corte IDH) (1987a). El hábeas corpus bajo suspensión de garantías. Opinión Consultiva 8/87. 30 de enero de 1987.

Corte Interamericana de Derechos Humanos (Corte IDH) (1987b). Garantías judiciales en Estados de Emergencia. Opinión Consultiva 9/87. 6 de octubre de 1987.

Corte Interamericana de Derechos Humanos (Corte IDH) (1994). La responsabilidad internacional por expedición y aplicación de leyes violatorias

LA LUCHA ANTITERRORISTA EN EL PERÚ: AGUJEROS NEGROS LEGALES, AGUJEROS GRISES Y EL ARDUO CAMINO CONSTITUCIONAL. LECCIONES

PERUANAS PARA

LA GUERRA

CONTRA EL TERRORISMO GLOBAL

THE ANTITERRORIST FIGHTING IN PERU: LEGAL BLACK HOLES, GRAY HOLES AND THE ARDUOUS CONSTITUTIONAL WAY. PERUVIAN LESSONS FOR THE WAR ON GLOBAL TERRORISM 
de la Convención (artículos 1 y 2 de la Convención Americana sobre Derechos Humanos). Opinión Consultiva 14.9 de diciembre de 1994.

Corte Interamericana de Derechos Humanos (Corte IDH) (1997a). Caso Loayza Tamayo vs. Perú. Sentencia. 17 de septiembre de 1997.

Corte Interamericana de Derechos Humanos (Corte IDH) (1997b). Caso Suárez Rosero vs. Ecuador. Sentencia. 12 de noviembre de 1997.

Corte Interamericana de Derechos Humanos (Corte IDH) (1999). Caso Castillo Petruzzi vs. Perú. Sentencia. 30 de mayo de 1999.

Corte Interamericana de Derechos Humanos (Corte IDH) (2000). Caso Cantoral Benavides vs. Perú. Sentencia. 18 de agosto de 2000.

Corte Interamericana de Derechos Humanos (Corte IDH) (2001). Caso Barrios Altos. Sentencia. 14 de marzo de 2001.

Corte Interamericana de Derechos Humanos (Corte IDH) (2006). Caso La Cantuta. Sentencia. 29 de noviembre de 2006.

Defensoría del Pueblo (2001). Amnistía vs. derechos humanos: buscando justicia. Informe 57. Lima.

Defensoría del Pueblo (2005). A dos años de la Comisión de la Verdad y Reconciliación. Informe 97. Lima.

Defensoría del Pueblo (2002). La desaparición forzada de personas en el Perú (1980-1996). Informe 55. Lima.

Defensoría del Pueblo (2013). A diez años de verdad, justicia y reparación. Avances, retrocesos y desafíos de un proceso inconcluso. Informe 162. Lima.

De la Jara, Ernesto (2001). Memoria y batallas en nombre de los inocentes (Perú 1992-2001) (segunda edición). Lima: IDL.

De la Jara, Ernesto (2003). El sistema de justicia durante los años de violencia: abdicación de funciones. En Ensayos sobre justicia y derechos humanos. Lima: Instituto de Defensa Legal.

De la Jara, Ernesto (2008). El papel de la sociedad política frente a la violencia política. En Luis Pásara (ed.), Perú en el siglo XXI. Lima: PUCP.

De Vergottini, Giuseppe (2004). La difícil convivencia entre libertad y seguridad. Respuesta de las democracias al terrorismo. Revista de Derecho Político, 61, 1136.

Durand, Francisco (2003). Riqueza económica y pobreza política. Reflexiones sobre las elites del poder en un país inestable. Lima: PUCP.

Dyzenhaus, David (2002). The Permanence of the Temporary: Can Emergency Powers be normalized? En Ronald J. Daniels y otros (eds.), The Security of Freedom: Essay on Canada's Anti-Terrorism Bill (21-38). Toronto: University of Toronto Press. 
Dyzenhaus, David (2006). The Constitution of Law: Legality in a Time of Emergency. Cambridge: Cambridge University Press.

Eguiguren Praeli, Francisco (2002). El derecho a la libertad personal: contenido, restricciones y protección frente a detenciones arbitrarias. En Estudios constitucionales. Lima: Ara Editores.

Francia, Luis (2006). Los procesos penales contra las organizaciones terroristas. En Lisa Magarrell y Leonardo Filippini (eds.), El legado de la verdad. La justicia penal en la transición peruana. Lima: CIJT/IDEHPUC.

Friedrich, Carl (1975). Gobierno constitucional y democracia. 2 tomos. Madrid: Instituto de Estudios Políticos.

García Cavero, Percy (2010). La autoría mediata por dominio de la voluntad en aparatos de poder organizados: el caso de Alberto Fujimori Fujimori. En Kai Ambos \& Iván Meini (eds.), La autoría mediata: el caso Fujimori. Lima: Ara.

Gorriti, Gustavo (2009). Sendero. Historia de la guerra milenaria en el Perú (segunda edición). Lima: Planeta.

Gross, Oren \& Fionnuala Ní Aoláin (2006). Law in Times of Crisis: Emergency Powers in Theory and Practice. Nueva York: CUP.

Landa Arroyo, César (2006). Estado constitucional y terrorismo en el Perú. En Constitución y fuentes del Derecho. Lima: Palestra Editores.

Landa Arroyo, César (2012). Executive Power and the Use of the State of Emergency. En Ana María Salinas de Frías y otros (eds.), Counter-terrorism: International Law and practice (205-231). Nueva York: Oxford University Press.

Lerner Febres, Salomón (2011). ¿Se aprendió la lección del conflicto armado interno? En Luis Pásara (ed.), Perú ante los desafíos del siglo XXI. Lima: PUCP.

Manrique, Nelson (2002). El tiempo del miedo: la violencia política en el Perú, 1980-1996. Lima: Fondo Editorial del Congreso de la República.

Meini, Iván (2010). El dominio de la organización de Fujimori. En Kai Ambos \& Iván Meini, La autoría mediata: el caso Fujimori. Lima: Ara.

Murakami, Yusuke (2012). Perú en la era del Chino: la política no institucionalizada y el pueblo en busca de un salvador (segunda edición). Lima: CIAS (Kyoto University)/ IEP.

Organización de las Naciones Unidas (ONU) (2010). Informe sobre la misión al Perú del Relator Especial de la ONU sobre la promoción y protección de los derechos humanos y las libertades fundamentales en la lucha contra el terrorismo, Martin Scheinin. Consejo de Derechos Humanos. A/HRC/16/51/ Add. 3. 15 de diciembre de 2010.

Pérez Aguilera, Mar (2012). Conflictividad social y vulneración de derechos. En Coordinadora Nacional de Derechos Humanos. Informe anual 2010-2011. Un año del gobierno de Ollanta Humala. Lima. 
Pérez Royo, Javier (2010). La democracia frente al terrorismo global. En Javier Pérez Royo (dir.), Terrorismo, democracia y seguridad, en perspectiva constitucional (pp. 7-12). Madrid: Marcial Pons.

Presidencia del Consejo de Ministros (2012). Decreto supremo 074-2012PCM. Diario Oficial El Peruano, 10 de julio de 2012.

Primera Sala Penal Transitoria de la Corte Suprema de Justicia (2009). Expediente 19-2001-09-AV. Sentencia. 30 de diciembre de 2009.

Román, Marlene (2009). La extradición de Alberto Fujimori: los aportes del derecho penal internacional y del derecho internacional de los Derechos Humanos. En Manuel Bermúdez Tapia (coord.), El caso Fujimori: análisis y comentarios. Lima: Caballero Bustamante.

Rositter, Clinton (2011). Constitutional Dictatorship: Crisis Government in the Modern Democracies. Nueva Jersey: Transaction Publishers.

Sala Penal Especial de la Corte Suprema de Justicia (2009). Casos Barrios Altos, La Cantuta y Sótanos del SIE. Expediente AV 19-2001 (acumulado). Sentencia. 7 de abril de 2009.

Sánchez Montenegro, Juan Pablo (2011). Las Fuerzas Armadas y el estado de emergencia como instrumento de su recuperación institucional durante el período 2001-2010. Tesis de Licenciatura en Ciencia Política. Lima: PUCP.

Soberón Garrido, Ricardo (2013). VRAEM: narcotráfico, terrorismo y militarización. En Werner Jungbluth M. (comp.), Perú hoy. El Perú subterráneo (pp. 103-132). Lima: DESCO.

Tribunal Constitucional (2003). Caso de la inconstitucionalidad de la legislación antiterrorista. STC 010-2002-AI/TC. 3 de enero de 2003.

Tribunal Constitucional (2004). Caso de la inconstitucionalidad de la legislación sobre el rol de las Fuerzas Armadas durante los regímenes de excepción. STC 0017-2003-AI/TC. 16 de marzo de 2004.

Tribunal Constitucional (2009). Caso de la inconstitucionalidad de la legislación sobre empleo de la fuerza por las Fuerzas Armadas en el territorio nacional. STC 00002-2008-PI/TC. 9 de septiembre de 2009.

Tushnet, Mark (2006). Defending Korematsu? Reflections on Civil Liberties in Wartime. En Mark Tushnet (ed.), The Constitution in Wartime: Beyond Alarmism and Complacency. Durham/Londres: Duke University Press, 2006.

Ugaz Sánchez-Moreno, José (1996). Libertad, seguridad personal y debido proceso. En Autores varios, La Constitución de 1993: análisis y comentarios III. Lima: CAJ/Konrad Adenauer Stiftung. 